\title{
Association between Stress and Dietary Behaviours among Undergraduate Students in Kuwait: Gender Differences
}

\author{
Ahmed $F^{*}$, Al-Radhwan L ${ }^{2}$, Al-Azmi GZS ${ }^{3}$ and Al-Beajan $\mathrm{M}^{4}$ \\ ${ }^{1}$ Public Health, School of Medicine and Griffith Health Institute, Griffith University, Gold Coast Campus, Australia \\ ${ }^{2}$ Nutrition Science, Quality Control Laboratory, Kuwait Flour Mills, Shuwaikh, Kuwait \\ ${ }^{3}$ Food and Nutrition Department, Al-Adan Hospital, Ministry of Health, Kuwait \\ ${ }^{4}$ Food and Nutrition Department, Mubarak al-Kbeer Hospital, Ministry of Health, Kuwait
}

*Corresponding author: Ahmed F, Public Health, School of Medicine and Griffith Health Institute, Griffith University, Gold Coast Campus, QLD 4222, Australia, E-mail: f.ahmed@griffith.edu.au

Citation: Ahmed F, Al-Radhwan L, Al-Azmi GZS, Al-Beajan M (2014) Association between Stress and Dietary Behaviours among Undergraduate Students in Kuwait: Gender Differences. J Nutr Health Sci 1(1): 104. doi: 10.15744/2393-9060.1.104

Received Date: February 28, 2014 Accepted Date: May 16, 2014 Published Date: May 20, 2014

Abstract
Background: Studies have shown that a significant proportion of university students globally suffer from stress. Although many stud-
ies have reported an association between psychological stress and dietary behaviour, findings remain inconclusive. To date, no research
in Kuwait has assessed the prevalence of stress and its relationship with dietary pattern among university students.
Objectives: This study was designed to determine the extent of stress among undergraduate students in Kuwait University and to ex-
amine the relationship between dietary behaviours and stress.
Methods: A total of 407 (164 males and 243 females) undergraduate students, aged $\geq 18$ years, from 4 colleges of Kuwait University
participated in this cross sectional study. Data were collected using a self-administered questionnaire consisting of three sections: socio
demographic information, stress measures and a 7 -day food frequency questionnaire.
Results: Of the total participants, $43 \%$ were found to suffer from some level of stress, with slightly more females (44\%) than males
(40.9\%). When examined the severity of stress level, $28.4 \%$ of the females and $22 \%$ of the males had moderate to severe form of stress.
Stressed female students were more likely to eat fast foods (OR 1.75 ; $95 \%$ CI: $1.02-3: 00)$, snacks (OR 2.0; $95 \%$ CI: $1.16-3: 43)$ and bev-
erages (OR $2.28 ; 95 \%$ CI: $1.30-3.98$ ) than unstressed female students. For male students, none of the food consumption groups were
associated with stress.
Conclusion: These results show a clear difference in food selection patterns between stressed male and female students with stress
being strongly associated with unhealthy food selection among female students than male students. These findings emphasize the
importance for the development of specific intervention programs to decrease stress and improve healthy behaviour especially among
female university students and thus reduce the potential negative implications of stress on health.

\section{Introduction}

Several studies around the globe have shown that university students experience high level of stress during their undergraduate program [1-5]. Difficulties of integrating into the new environment, academic workload and time management were identified as the major causes of stress among the undergraduate university students [5]. Further, studies have shown there to be an association between stress and health. For example, chronic stress can lead to increased blood pressure, cardiovascular disease, diabetes, suppressed immunity and an increased incidence of depression [6-7]. Furthermore, chronic stress is also found to be associated with increased risk of obesity [8], which is an underlying factor that contribute to the chronic diseases such as cardiovascular disease and diabetes.

There is evidence to support that stress can affect an individual's health not only through direct physiological processes but also by altering behaviours which affect health [9-10]. Change in diet patterns is one such health behavioural response to stress observed in different population groups. Some studies have shown that stressed individuals tended to increase consumption of high calorie and high fat snack foods [9-10], which may culminate in weight gain and obesity [11]. While there is widespread scientific acceptance of a relationship between psychological stress and eating behaviours [12], the findings are inconsistent. Individuals have been found to respond to stress with either reduced (hypophagia) or increased food intake (hyperphagia) [10,13-14]. As well as the amount, the type of food eaten is affected by stress. The intake of snack type foods, pre-prepared ready-to-eat foods and sweet foods such as chocolate, cakes and ice-cream, was found to increase among students experiencing stress [10,14-16]; while the intake of healthy food such as vegetables tended to decrease [9-10]. 
Food selection patterns associated with stress have also been reported to vary by gender [10,17]. Studies have shown that although females tended to be more health conscious (i.e. opting for low calorie foods) than men during non- stress periods [18-19], when stressed females were more likely to increase consumption of high sugar, high fat foods and unhealthy snacking; while reducing intakes of healthier foods like vegetables [19]. Some of the studies focused on stressed male food behavior found no effect on food selection [17], while other studies reported an increase in the consumption of red meat, pizza and soda [20]. Further, one longitudinal prospective study reported a strong hypophagic response to stress among women than men [21]. There has been a suggestion that these gender differences may have reflected differences in dietary restraint, which is known to be higher in women [22-23].

Kuwait has one of the highest rates of overweight and obesity globally. One recent study has indicated that over half of the college students are either overweight or obese [24]. Further, the prevalence is higher among females than males [24]. To date, little data is published on food choices of university students in Kuwait. A pilot study found the intakes of healthy fats, water and vegetables were below the recommended intake levels, but $86.5 \%$ of participants consumed sweet and fatty foods in excess of the recommended amounts [25]. Further, a recent study also reported a poor nutrition knowledge among Kuwaiti college students [26]. However, no studies have explored the link between stress and dietary behaviour in this segment of the population. If stressinduced eating is contributing to development of obesity, it is important to examine such association in order to combat obesity epidemic in the country. Further, one defining characteristic of these young adults is the development of self-identity, which is an important indicator of lasting health behaviour change [27], thus the dietary behaviours followed during this period may set the stage of establishing long-term behaviours that can have life-time disease [28]. Hence, an accurate understanding of the prevalence of stress and diet related response in this young population would enable health professionals to develop more effective intervention programs for helping them cope with stress without negatively impacting on their health behaviors. The present study was designed to determine the extent of stress among undergraduate students in Kuwait University and to examine the relationship between dietary behaviours and stress.

\section{Subjects and Methods}

\section{Study design and participants}

A cross sectional study design was used to collect data from undergraduate students of Kuwait University. Out of sixteen colleges, 4 colleges were selected using simple random sampling technique. A total of 407 students (164 males and 243 females) from the Education College, Al-Sharia’a and Islamic Studies College, Science College and Engineering and Petroleum College participated in the study. The students who reported trying to lose weight or on a restrained diet and/or who had any chronic diseases (diabetes, hypertension, colon or cardiovascular disease) were excluded from the study. The study was approved by the Department of Family Sciences, College for Women, Kuwait University, Kuwait.

\section{Sampling}

Sampling method applied in this study was a purposive sampling. The participants were addressed before the questionnaire was administered during lecture time and were informed about the purpose of the research. After obtaining the verbal consent, a self-administrated pre-tested questionnaire was distributed to the students in the lecture room during the half way through of fall semester.

\section{Data collection}

The questionnaire was comprised of three sections: socio-demographic, stress measures, and dietary pattern for selected food items.

Socio-demographic: The socio-demographic section gathered information on area of study and year of study, age, sex, marital status, smoking status, family income and parent's education level.

Stress assessment: In section two, stress among undergraduate university students was assessed using the self-report Depression Anxiety Stress Scales (DASS). The DASS has been validated successfully for different populations and is a popular tool for assessing the severity of the main symptoms for depression, anxiety and stress among researchers [29]. The reliability of the stress scales is considered adequate with Cronbach's alpha $=0.93$ [30]. This study only used one section of the DASS, the stress scale section. The stress scale section consists of 14 items that assess difficulty relaxing, nervous arousal, and being easily upset/agitated, irritable/ over-reactive and impatient [31]. The DASS scale uses a 4-point Likert scale of frequency or severity to rate the degree of stress experienced by participants during the previous week period [29]. The 4-point scale ranges from 0 , which means that the participant feels that the item "did not apply to them at all" to 3, whereby the participant feels that the item "applied to them very much, or most of the time". Individuals' stress scores were calculated by summing up all of the scores from the 14 items and then comparing those scores to the cutoff scores for normal, mild, moderate, severe and very severe stress levels found in the DASS Manual [31]. 
Dietary pattern: In section three, dietary pattern of the participants was assessed using 7-day food frequency questionnaire (FFQ). For the purpose of this study, a range of food and beverage items were identified as having a high fat and/or sugar contents (eg. energy dense foods) and thus considered as unhealthy food. To identify whether stress-induced eating only triggers more palatable food items, such as snacks or any type of energy dense foods, the selected unhealthy food items were further categorized into three groups: fast foods (such as hamburger, kebab, pizza, french fries, and chicken nuggets); snacks (such as potato chips, ice cream/milk shake, cakes, muffins and candy); and beverages (fruit juice, tea, coffee, soft drink, and energy drinks). In addition, to examine whether stress influences healthy eating behaviour, fruits and vegetables (leafy and non-leafy vegetables) were included as a proxy of healthy food items. The FFQ was developed to collect information on both healthy and unhealthy foods based on selected food items. The frequency of consumption for each food or beverage in the past week was converted into a daily equivalence as follows: not in the past week (0.00 per day), once a week ( 0.14 per day), 2-3 times a week (0.35 per day), 4-6 times a week (0.70 per day) and 7 times or more a week (1.00 per day). The FFQ was focused on the frequency of selected food items and information on the portion size was not included. In order to ensure face and content validity, a pilot study was undertaken to pre-test the questionnaire on a group of university students who were not involved in this research and then finalised the questionnaire.

Statistical analysis: The frequency distributions for all variables were estimated. The proportions for the categorical variables were calculated and chi-square test was used to examine the differences between genders. All socio-demographic variables were divided into subgroups as follows: age (18-19 and 20-24 year), year of study (first, second, third and fourth year), and the family income into three categories (<1000 KD, 1000-2000 KD and > $2000 \mathrm{KD}$ ), parents' education level (primary or less, secondary, diploma and above), marital status (single and married) and smoking status (smoker and non-smoker). Further, the proportion of males and females students who exceeded the specific cut-off scores for various stress levels was calculated.

As the distribution of frequency of consumption of all food items were skewed, the differences in consumption frequency of various foods between students with and without stress were assessed using Mann-Whitney test. The analyses were done for males and females separately. The association between stress and dietary behaviours was assessed using logistic regression analysis for male and females separately. The four food groups (fast food, snacks, beverages and healthy food) were treated as outcome (dependent) variables and stress as independent variable. Further, age, marital status, smoking status, parent's education and family income categories were used as confounding variables. Each of the outcome variables (food groups) was dichotomized using the median value. The independent variable (stress) was also dichotomized by no stress (reference category) and stress (mild, moderate, severe and very severe combined). Results of the regression analyses are presented as odds ratios adjusted for confounding variables. A $P$ value of 0.05 or less was considered statistically significant. The statistical analysis was performed using SPSS statistical software (SPSS Inc, Chicago, SPSS for Windows, version 20.0).

\section{Results}

Of the total participants $(n=407), 40 \%$ were male and $60 \%$ were female. Nearly half $(48.8 \%)$ of the females and about $40 \%$ of the males were aged between 18-19 years (Table 1). Large majority (83-90\%) of the participants were unmarried or single. However, a significantly higher proportion of females (16.9\%) than males $(9.8 \%)$ were married. About $13 \%$ of both males and females were fourth year students, while the rest were almost equally distributed between $1^{\text {st }}, 2^{\text {nd }}$ and $3^{\text {rd }}$ year. Nearly a quarter of the male students were smokers, while it was only $2.5 \%$ for females. More than half of the students had at least one parent with diploma or higher education status, the remainder were fairly evenly split between the remaining two categories; secondary (23.6\%) and primary $(22.1 \%)$. Over one-third of the students came from a family with an income $<1000 \mathrm{KD} / \mathrm{month}$ and about one-fifth came from the highest $(>2000 \mathrm{KD}) /$ month income group. The rest came from families with income between $1000-2000 \mathrm{KD} / \mathrm{month}$.

Overall, $43 \%$ of the participants were found to suffer from some level of stress, with relatively more (44\%) females than males (40.9). When severity of stress level was considered, $15.6 \%$ of the females were suffering from mild stress, $18.1 \%$ had moderate stress and $10.3 \%$ had severe stress. Among males, only $7.4 \%$ has severe stress, $14.6 \%$ had moderate stress and another $18.9 \%$ had mild stress (Table 1). However, these differences between genders were not statistically significant.

Table 2 shows the differences in consumption of different foods within gender groups by stress. Among female students who were stressed had significantly higher frequency of intakes of burger $(\mathrm{P}=0.005)$, french fries $(\mathrm{P}=0.02)$, cake/brownies/cookies/ chocolate $(\mathrm{P}=0.04)$, muffins/doughnuts/pastries $(\mathrm{P}=0.006)$, tea $(\mathrm{P}=0.03)$, coffee $(\mathrm{P}=0.007)$ and energy drinks $(\mathrm{P}=0.001)$ than unstressed female students. When analysis was done after combining different food items into similar food group categories, stressed female students had significantly higher consumption of total fast foods $(\mathrm{P}=0.01)$, total snack foods $(\mathrm{P}=0.002)$ and total beverages $(\mathrm{P}=0.001)$ than unstressed female students. In contrast, no statistically significant difference in intake of any of the food items was observed between stressed male students and unstressed male students. However, frequency of intake of total fast foods was significantly $(\mathrm{P}=0.04)$ higher among stressed male students.

Logistic regression analysis was used to examine the association between stress and food consumption pattern among males and females separately (Table 3). In this analysis various unhealthy and healthy food groups were used as outcome variables. Stressed female students were more likely to consume fast foods (OR 1.75; 95\% CI: 1.02-3.00), snacks (OR 2.0; 95\%CI: 1.16-3.43) and beverages (OR 2.28; 95\%CI: 1.30-3.98) than unstressed female students. In contrast, stress did not influence the dietary pattern among male students. 


\begin{tabular}{|c|c|c|c|c|c|}
\hline \multirow[t]{2}{*}{ Variables } & \multicolumn{2}{|c|}{ Male } & \multicolumn{2}{|c|}{ Female } & \multirow[b]{2}{*}{ P-value } \\
\hline & $\mathrm{n}$ & $\%$ & $\mathrm{n}$ & $\%$ & \\
\hline \multicolumn{6}{|l|}{ Age group (Year) } \\
\hline $18-19$ & 66 & 40.5 & 118 & 48.8 & \\
\hline $20-24$ & 97 & 59.5 & 124 & 51.2 & 0.10 \\
\hline \multicolumn{6}{|l|}{ Level of study } \\
\hline $1^{\text {st }}$ Year & 46 & 28.0 & 73 & 30.0 & \\
\hline $2^{\text {st }}$ Year & 52 & 31.8 & 72 & 29.6 & 0.96 \\
\hline $3^{\text {rd }}$ Year & 44 & 26.8 & 66 & 27.2 & \\
\hline $4^{\text {th }}$ Year & 22 & 13.4 & 32 & 13.2 & \\
\hline \multicolumn{6}{|l|}{ Marital status } \\
\hline Single & 148 & 90.2 & 202 & 83.1 & \\
\hline Married & 16 & 9.8 & 41 & 16.9 & 0.04 \\
\hline \multicolumn{6}{|l|}{ Smoking status } \\
\hline Smoker & 38 & 23.3 & 6 & 2.5 & \\
\hline Non-smoker & 125 & 76.7 & 237 & 97.5 & 0.001 \\
\hline \multicolumn{6}{|l|}{ Father's education level } \\
\hline Primary or less & 36 & 22.0 & 47 & 19.3 & \\
\hline Secondary & 32 & 19.5 & 67 & 27.6 & 0.18 \\
\hline Diploma or above & 96 & 58.5 & 129 & 53.1 & \\
\hline \multicolumn{6}{|c|}{ Mother's education level } \\
\hline Primary or less & 39 & 23.8 & 57 & 23.5 & \\
\hline Secondary & 35 & 21.3 & 63 & 25.9 & 0.55 \\
\hline Diploma or above & 90 & 54.9 & 123 & 50.6 & \\
\hline \multicolumn{6}{|l|}{ Family income group } \\
\hline$<1000 \mathrm{KD}$ & 56 & 34.4 & 84 & 34.9 & \\
\hline $1001-2000 \mathrm{KD}$ & 71 & 43.6 & 107 & 44.4 & 0.95 \\
\hline$>2000 \mathrm{KD}$ & 36 & 22.0 & 50 & 20.7 & \\
\hline \multicolumn{6}{|l|}{ Stress level } \\
\hline Normal & 97 & 59.1 & 136 & 56.0 & \\
\hline Mild & 24 & 14.6 & 38 & 15.6 & \\
\hline Moderate & 31 & 18.9 & 44 & 18.1 & 0.75 \\
\hline Severe & 12 & 7.4 & 25 & 10.3 & \\
\hline
\end{tabular}

${ }^{*}$ Chi-square test.

Table 1: Socio-demographic characteristics of the study participants by gender. 


\begin{tabular}{|c|c|c|c|c|c|c|c|c|c|c|}
\hline & \multicolumn{5}{|c|}{ Male } & \multicolumn{5}{|c|}{ Female } \\
\hline & \multicolumn{2}{|c|}{ Normal } & \multicolumn{2}{|c|}{ Stressed } & \multirow[b]{2}{*}{ P-value } & \multicolumn{2}{|c|}{ Normal } & \multicolumn{2}{|c|}{ Stressed } & \multirow[b]{2}{*}{ P-value } \\
\hline & Median & Range & Median & Range & & Median & Range & Median & Range & \\
\hline \multicolumn{11}{|l|}{ Fast Food } \\
\hline Burger & 0.35 & $0.0-1.0$ & 0.35 & $0.0-1.0$ & 0.08 & 0.14 & $0.0-1.0$ & 0.35 & $0.0-1.0$ & 0.005 \\
\hline Chicken nuggets & 0.14 & $0.0-1.0$ & 0.14 & $0.0-1.0$ & 0.34 & 0.14 & $0.0-1.0$ & 0.14 & $0.0-1.0$ & 0.76 \\
\hline Sausage/Hot dog & 0.14 & $0.0-1.0$ & 0.14 & $0.0-1.0$ & 0.08 & 0.14 & $0.0-1.0$ & 0.14 & $0.0-1.0$ & 0.56 \\
\hline Pizza & 0.14 & $0.0-1.0$ & 0.14 & $0.0-1.0$ & 0.19 & 0.14 & $0.0-1.0$ & 0.14 & $0.0-1.0$ & 0.47 \\
\hline French fries & 0.35 & $0.0-1.0$ & 0.35 & $0.0-1.0$ & 0.43 & 0.35 & $0.0-1.0$ & 0.35 & $0.0-1.0$ & 0.02 \\
\hline Total fast food & 1.19 & $0.0-4.35$ & 1.57 & $\begin{array}{l}0.0- \\
4.35\end{array}$ & 0.04 & 1.05 & $0.0-5.0$ & 1.42 & $0.14-4.3$ & 0.01 \\
\hline \multicolumn{11}{|l|}{ Snacks } \\
\hline Chips & 0.35 & $0.0-1.0$ & 0.35 & $0.0-1.0$ & 0.39 & 0.35 & $0.0-1.0$ & 0.35 & $0.0-1.0$ & 0.06 \\
\hline $\begin{array}{l}\text { Cake/Brownies/Cookies/ } \\
\text { Chocolate }\end{array}$ & 0.35 & $0.0-1.0$ & 0.35 & $0.0-1.0$ & 0.44 & 0.35 & $0.0-1.0$ & 0.70 & $0.0-1.0$ & 0.04 \\
\hline Muffins/Doughnuts/Pastries & 0.14 & $0.0-1.0$ & 0.14 & $0.0-1.0$ & 0.79 & 0.35 & $0.0-1.0$ & 0.35 & $0.0-1.0$ & 0.006 \\
\hline Ice-cream/milk shake & 0.14 & $0.0-1.0$ & 0.14 & $0.0-1.0$ & 0.94 & 0.35 & $0.0-1.0$ & 0.35 & $0.0-1.0$ & 0.42 \\
\hline Total snacks & 1.19 & $0.0-3.70$ & 1.19 & $0.0-4.0$ & 0.80 & 1.14 & $0.0-4.0$ & 1.89 & $0.0-4.0$ & 0.002 \\
\hline \multicolumn{11}{|l|}{ Beverages } \\
\hline Fruit juice & 0.70 & $0.0-1.0$ & 0.70 & $0.0-1.0$ & 0.31 & 0.70 & $0.0-1.0$ & 0.70 & $0.0-1.0$ & 0.32 \\
\hline Tea & 0.35 & $0.0-1.0$ & 0.53 & $0.0-1.0$ & 0.22 & 0.35 & $0.0-1.0$ & 0.35 & $0.0-1.0$ & 0.03 \\
\hline Coffee & 0.35 & $0.0-1.0$ & 0.35 & $0.0-1.0$ & 0.61 & 0.14 & $0.0-1.0$ & 0.35 & $0.0-1.0$ & 0.007 \\
\hline Soft drink & 0.35 & $0.0-1.0$ & 0.35 & $0.0-1.0$ & 0.74 & 0.35 & $0.0-1.0$ & 0.35 & $0.0-1.0$ & 0.14 \\
\hline Energy drink & 0.00 & $0.0-1.0$ & 0.14 & $0.0-1.0$ & 0.09 & 0.00 & $0.0-1.0$ & 0.00 & $0.0-1.0$ & 0.001 \\
\hline Total beverages & 2.05 & $\begin{array}{l}0.14- \\
4.35\end{array}$ & 2.54 & $\begin{array}{c}0.28- \\
5.0\end{array}$ & 0.14 & 1.63 & $0.35-5.0$ & 2.05 & $0.14-4.7$ & 0.001 \\
\hline \multicolumn{11}{|l|}{ Healthy Food } \\
\hline Leafy vegetables & 0.35 & $0.0-1.0$ & 0.35 & $0.0-1.0$ & 0.94 & 0.35 & $0.0-1.0$ & 0.35 & $0.0-1.0$ & 0.71 \\
\hline Non-leafy vegetables & 0.14 & $0.0-1.0$ & 0.14 & $0.0-1.0$ & 0.77 & 0.14 & $0.0-1.0$ & 0.35 & $0.0-1.0$ & 0.60 \\
\hline Fruit & 0.35 & $0.0-1.0$ & 0.35 & $0.0-1.0$ & 0.61 & 0.35 & $0.0-1.0$ & 0.35 & $0.0-1.0$ & 0.92 \\
\hline
\end{tabular}

Table 2: Differences in frequency of intakes of various fast foods, snacks and beverages between students with stress and students with no stress by gender.

\begin{tabular}{|c|c|c|c|c|c|c|}
\hline \multirow[b]{2}{*}{ Food items } & \multicolumn{3}{|c|}{ Male } & \multicolumn{3}{|c|}{ Female } \\
\hline & Adjusted $\mathrm{OR}^{*}$ & $95 \% \mathrm{CI}$ & P-value & Adjusted $\mathrm{OR}^{\star}$ & $95 \% \mathrm{CI}$ & P-value \\
\hline \multicolumn{7}{|l|}{ Unhealthy Food } \\
\hline Fast Food & 1.75 & $0.85-3.60$ & 0.13 & 1.75 & $1.02-3.00$ & 0.044 \\
\hline Snacks & 1.01 & $0.50-2.03$ & 0.98 & 2.00 & $1.16-3.43$ & 0.013 \\
\hline Beverages & 1.57 & $0.78-3.17$ & 0.21 & 2.28 & $1.30-3.98$ & 0.004 \\
\hline \multicolumn{7}{|l|}{ Healthy Food } \\
\hline Non-Leafy vegetables & 0.69 & $0.34-1.41$ & 0.31 & 0.63 & $0.36-1.09$ & 0.098 \\
\hline Leafy vegetables & 0.94 & $0.45-1.95$ & 0.86 & 1.29 & $0.68-2.44$ & 0.43 \\
\hline Total vegetables & 0.76 & $0.37-1.53$ & 0.43 & 0.63 & $0.37-1.09$ & 0.102 \\
\hline Fruit & 0.82 & $0.38-1.77$ & 0.62 & 1.07 & $0.56-2.03$ & 0.84 \\
\hline
\end{tabular}

${ }^{*}$ Using logistic regression analysis, the data were adjusted for age, marital status, smoking status, parent's education and family income.

All food groups were dichotomized using a frequency of intake cut-off of median value/day.

Table 3: Odds ratios for various food consumption groups associated with stress among Kuwait University students by gender. 


\section{Discussion}

The present study revealed that more than $40 \%$ of the undergraduate students in Kuwait University suffer from some level of stress. Several studies across the world have also shown high prevalence of stress among university students [1-5] and thus the findings of the present study add further evidence to current literature. In a study among Malaysian university students stress was observed among $36 \%$ of the respondents [1]. Another study reported a prevalence of $43 \%$ among first year tertiary education students in Hong Kong [2]. However, a much higher prevalence of stress was observed among students in western countries and in other Middle Eastern countries, for example 83.9\% in Australia [3], 63.8\% in Saudi Arabia [4], 61.3\% in Iran [32] and 70\% in Jordan [33]. The difference in prevalence of stress reported among university students in different countries may, to some extent, be due to the differences in methods used to determine stress. Moreover, some studies reported perceived stress [3], thus makes it difficult to compare between studies. Another important reason that may have contributed to the differences in the observed prevalence of stress is the socio-cultural characteristics of the study participants. However, it is important to recognize the fact that studies have shown that the prevalence of psychological distress may vary according to the academic time of the year [3]. Further, research has shown that first year students were at an increased risk of poor mental health [2] with the prevalence of stress decreasing as students progressed to higher years [34].

It is worth noting the rate of stress symptoms of moderate to severe level as such symptom levels are likely to lead to some functional impairments which may have adverse effect on their physical and mental health development, educational attainment and productivity and overall quality of life $[2,34]$. Thus when considered the severity of stress level, over a quarter of the Kuwaiti students were found to be at moderate to severe state of stress. In the present study we used DASS screening tool to measure stress and the prevalence of moderate to severe stress level observed in this study was very similar to that of the university students in Malaysia [1], Hong Kong [2] and Turkey [34], who also assessed the stress level using DASS stress screening tool and thus the results are highly comparable.

In this study, although the overall prevalence of stress was higher among female (44\%) than male (41\%) students, the difference was not statistically significant, a finding similar to that was observed among undergraduate music students in Turkey [35]. On contrary, the prevalence of stress was significantly higher among female than male students in Hong Kong [2], Malaysia [1] and in Saudi Arabia [4]. The inconsistency in the finding of the gender differences could be due the differences in characteristics of the participants or simply socio-cultural differences. For example, traditionally Kuwaiti women are rarely involved in sport club, free movement and other social activities compared to Kuwaiti men [36].

In this study, we examined the relationship between stress and food selection pattern among male and female students separately. The results of the bivariate analysis revealed that the stressed females ate significantly more of the unhealthy energy dense foods than the unstressed females. Such changes in dietary behaviours were not observed in stressed male students, except for significantly higher total fast food intake. Since socio-demographic status are known to affect the dietary behaviors of a population, in the present study, logistic regression analysis was conducted to examine the independent association between stress and food selection pattern among male and females students separately after controlling for various socio-demographic variables. The results of logistic regression showed that stressed females were 1.75, 2.00 and 2.28 times more likely to take fast foods, snacks and beverages respectively, than unstressed female students. For male students, none of the food consumption groups were found to be associated with stress. A study conducted among students in three European countries also showed very similar results with the exception of fruits/vegetables consumption [37]. In the present study, we did not find any association between stress and consumption pattern of healthy food such as fruits and vegetables in either male or female students.

One laboratory experimental study also reported that women who are stressed ate more unhealthy food (snacks- chocolate/candies) than women who are not stressed, while unstressed men had significantly higher consumption of unhealthy foods than did men in the stress group [17]. Further, a number of other studies also reported a higher consumption of 'unhealthy' eating among stressed females [13-15]. One study found that although $80 \%$ of their female study participants reported that they typically ate a healthy diet, that only $34 \%$ of these females ate healthy foods when stressed [13]. Similarly, two other studies both reported that when distressed, their female study participants appeared to lose control of their eating habits which resulted in their consumption the unhealthy foods that they would usually avoid for health or weight motives $[10,15]$. One explanation for the gender difference in food selection patterns during stress may be the tendency of females to restrict their diet for weight control when not stressed [38-39]. It is important to note that in the present study we excluded students who reported trying to lose weight or on a restrain diet and thus the unhealthy eating behaviour of stressed females most likely the influence of stress only. The present finding provides further evidence of association between stress and unhealthy eating patterns among females without any dietary restriction, and thus emphasizing the need for considering potential confounders while conducting such studies.

This study has some limitations. One limitation is related to sampling method. The sample selection was based on a purposive sampling, thus it limits the generalizability of the study. However, regardless of sampling method, this study made an attempt to identify stress using a well-validated instrument and still more than 40 percent of students were found have some level of stress. These numbers certainly draws attention to the extent of stress levels among students. Another limitation is that the present study could not establish that the stress directly compromises the healthy eating behaviours. 
It does however demonstrate an association between stress and poor dietary behaviours particularly among female students, which is important for the development of specific programs to decrease stress and improve healthy behaviour among female university students. Although some evidence exists indicating an educational intervention to increase dietary knowledge might be useful among Kuwaiti students [25], environmental interventions will also be needed. For example, ensuring healthy food options are cheap and widely prevalent throughout the community as well as in the university campus.

In conclusion, the findings of the present study suggest that a significant proportion of undergraduate students in Kuwait suffers from stress. Further, this study revealed that the stress increases the selection of unhealthy foods in female students, while it has little effect on food selection in stressed male students. The development of university programs should be focused on how to provide the knowledge and resources for students, especially for female students, to healthfully cope with stress and thus reduce the potential negative implications of stress on health.

\section{Acknowledgement}

FA took the lead in study planning and design, provided guidance on the data collection and analysis of the data, and wrote the manuscript. LA, GA and MA collected the data, contributed to the study planning and writing of the manuscript. Special thanks to Ms. Noor Ayad for helping in data collection.

\section{References}

1. Gan WY, Nasir MT, Zalilah MS, Hazizi AS (2011) Disordered Eating Behaviors,Depression, Anxiety and Stress Among Malaysian University Students. College Student Journal 45: 296-309.

2. Wong JG, Cheung EP, Chan KK, Ma KK, Tang SW (2006) Web-based survey of depression, anxiety and stress in first-year tertiary education students in Hong Kong. Aust N Z J Psychiatry 40: 777-82.

3. Stallman HM (2010) Psychological distress in university students: A comparison with general population data. Australian Psychologist 45: $249-57$.

4. Abdulghani HM, AlKanhal AA, Mahmoud ES, Ponnamperuma GG, Alfaris EA (2011) Stress and its effects on medical students: a cross-sectional study at a college of medicine in Saudi Arabia. J Health Popul Nutr 29: 516-22.

5. Britz J, Pappas E (2010) Sources and outlets of stress among university students: correlations between stress and unhealthy habits. URJHS 9.

6. Schneiderman N, Ironson G, Siegel SD (2005) Stress and health: psychological, behavioral, and biological determinants. Annu Rev Clin Psychol 1: 607-28.

7. Ohman L, Nyberg L, Bergdahl J, Nilsson LG (2007) Longitudinal analysis of the relation between moderate and long-term stress and health. Stress and health. Journal of the International Society for the Investigation of stress 23: 131-8.

8. Torres SJ, Nowson CA (2007) Relationship between stress, eating behavior, and obesity. Nutrition 23: 887-94.

9. Unusan N (2006) Linkage between stress and fruit and vegetable intake among university students: an empirical analysis on Turkish students. Nutrition Research 26: 385-90.

10. Zellner DA, Loaiza S, Gonzalez Z, Pita J, Morales J, et al. (2006) Food selection changes under stress. Physiol Behav 87: 789-93.

11. Laitinen J, Ek E, Sovio U (2002) Stress-related eating and drinking behavior and body mass index and predictors of this behavior. Prev Med $34: 29-39$.

12. Greeno CG, Wing RR (1994) Stress-induced eating. Psychol Bull 115: 444-64.

13. Kandiah J, Yake M, Jones J, Meyer M (2006) Stress influences appetite and comfort food preferences in college women. Nutrition Research 26: 118-123.

14. Oliver G, Wardle J (1999) Perceived effects of stress on food choice. Physiol Behav 66: 511-5.

15. Liu C, Xie B, Chou CP, Koprowski C, Zhou D, et al. (2007) Perceived stress, depression and food consumption frequency in the college students of China Seven Cities. Physiol Behav 92: 748-54.

16. Serlachius A, Hamer M, Wardle J (2007) Stress and weight change in university students in the United Kingdom. Physiol Behav 92: 548-53.

17. Zellner DA, Saito S, Gonzalez J (2007) The effect of stress on men's food selection. Appetite 49: 696-9.

18. Economos CD, Hildebrandt ML, Hyatt RR (2008) College freshman stress and weight change: differences by gender. Am J Health Behav $32: 16-25$.

19. Sharma B, Harker M, Harker D,Reinhard K (2010) Youth transition to university in Germany and Australia: an empirical investigation of healthy eating behaviour. Journal of Youth Studies 13: 353-67.

20. Ng DM, Jeffery RW (2003) Relationships between perceived stress and health behaviors in a sample of working adults. Health Psychol $22: 638-42$.

21. Stone AA, Brownell KD (1994) The stress-eating paradox: Multiple daily measurements in adult males and females. Psychology and Health 9: 425-36.

22. Johnson WG, Corrigan SA, Schlundt DG, Dubbert PM (1990) Dietary restraint and eating behavior in the natural environment. Addict Behav 15: 285-90.

23. Weinstein SE, Shide DJ, Rolls BJ (1997) Changes in food intake in response to stress in men and women: psychological factors. Appetite 28: 7-18.

24. AlMajed HT, AlAttar AT, Sadek AA, AlMuaili TA, AlMutairi QA, et al. (2011) Prevalence of dyslipidemia ad obesity among college students in Kuwait. Alexandria Journal of Medicine 47: 67-71.

25. Al-Khamees NA (2009) Food habits of university nutrition students: pilot study. Nutrition \& Food Science, 39: $499-502$.

26. Al-Isa A, Alfaddagh A (2014) Nutritional knowledge among kuwaiti college students. Health 6: 448-453.

27. Nelson MC, Story M, Larson NI, Neumark-Sztainer D, Lytle LA (2008) Emerging adulthood and collecge aged youth: An overlooked age for weight-related behavior change. Obesity 16: 2205-11.

28. Nelson LM, Larson NI, Neumark-Sztainer D, Story M (2010) Dietary patterns and home food availability during emerging adulthood: do they differ by living situation? Public Health Nutr 13: 222-8.

29. Crawford JR, Henry JD (2003) The Depression Anxiety Stress Scales (DASS): normative data and latent structure in a large non-clinical sample. Br J Clin Psychol 42: 111-31. 
30. Brown TA, Chorpita BF, Korotitsch W, Barlow DH (1997) Psychometric properties of the Depression Anxiety Stress Scales (DASS) in clinical samples. Behav Res Ther 35: 79-89.

31. Lovibond SH, Lovibond PF (1995) Manual for the Depression Anxiety Stress Scales $2^{\text {nd }}$ Edition. Psychological Foundation.

32. Koochaki GM, Charkazi A, Hasanzadeh A, Saedani M, Qorbani M, et al. (2011) Prevalence of stress among Iranian medical students: a questionnaire survey. Eastern Mediterranean Health Journal 17: 593-8.

33. Abu-Ghazaleh SB, Rajab LD, Sonbol HN (2011) Psychological stress among dental students at the University of Jordan. Journal of Dental Education 75: 110714.

34. Bayram N, Bilgel N (2008) The prevalence and socio-demographic correlations of depression, anxiety and stress among a group of university students. Social Psychiatry and Psychiatric Epidemiology 43: 667-72.

35. Demirbatir RE (2012) Undergraduate music students' depression, anxiety and stress levels: a study from Turkey. Procedia Social and Behavioral Sciences 46: 2995-9.

36. Al-Kandari YY (2006) Prevalence of obesity in Kuwait and its relationship to socio-cultural variables. Obesity Reviews 7: 147-54.

37. Mikolajczyk RT, El Ansari W, Maxwell AE (2009) Food consumption frequency and perceived stress and depressive symptoms among students in three European countries. Nutr J 8: 31.

38. Sira N, Pawlak R (2010) Prevalence of overweight and obesity, and dieting attitudes among Caucasian and African American college students in Eastern North carolina: A cross-sectional survey. Nutr Res Pract 4: 36-42.

39. Yahia N, El-Ghazale H, Achkar A, Rizk S (2011) Dieting practices and body image perception among Lebanese university students. Asia Pac J Clin Nutr 20: 21-8. 